\title{
Using urinary neutrophile gelatinase- associated lipocalin for prognosticate renal dysfunction in children with familial Mediterranean fever the study design: a pilot study
}

\author{
Sinem Can Oksay ${ }^{1}$, Hasan Dursun ${ }^{2,3^{*}}$, Sebnem Tekin Neijmann ${ }^{4}$ and Sami Hatipoglu ${ }^{1}$
}

\begin{abstract}
Background: The most important finding that affects the prognosis in Familial Mediterranean Fever is renal amyloidosis. The aim of the present study was to analyze neutrophil gelatinase-associated lipocalin levels in the urine, and to investigate whether it may be used as an early marker for renal involvement.
\end{abstract}

Methods: Forty attack-free children followed by diagnosis of Familial Mediterranean Fever with age range of 5 and 18 years, and 38 healthy children with similar ages and genders were enrolled into the study. Hemogram, sedimentation, C-reactive protein, urine analysis, creatinine in the spot urine, microalbumin and urinary neutrophil gelatinase-associated lipocalin levels were analyzed and evaluated statistically in the patients and controls.

Results: There was not any statistically significant difference between the patient and control groups for age, gender, height and body weight. Although there was not any clinical sign of attack in the patient group, sedimentation, C-reactive protein and fibrinogen levels were significantly higher than the control group ( $p=0.002$, $p=0.023$, and $p=0.006$, respectively). Similarly, urinary neutrophil gelatinase-associated lipocalin level and urinary creatinine ratio were significantly higher in the patient group $(p=0.0001, p=0.011$, respectively). We found a positive correlation between UNGAL level and UNGAL/uCr ratio and number of attacks per year in FMF patients ( $r=0.743, p=0.001$ and $r=0.516, p=0.001$; respectively).

Conclusions: Detection of significantly higher levels of urinary neutrophil gelatinase-associated lipocalin level and urinary neutrophil gelatinase-associated lipocalin level to creatinine ratio were suggested as urinary neutrophil gelatinase-associated lipocalin level as a non-invasive marker for renal involvement better than microalbumin.

Keywords: Familial Mediterranean fever, Urinary neutrophil gelatinase-associated lipocalin

\footnotetext{
* Correspondence: dursunhs@yahoo.com

${ }^{2}$ Dr. Sadi Konuk Training and Research Hospital Department of Pediatric Nephrology, Health Science University, Istanbul, Turkey

${ }^{3}$ Okmeydani Training and Research Hospital Department of Pediatric

Nephrology, Health Science University, Kaptan Paşa Mahallesi, Darülaceze

Cad. No: 25 Okmeydani, 34384 Şişli/lstanbul, Turkey

Full list of author information is available at the end of the article
}

(c) The Author(s). 2021 Open Access This article is licensed under a Creative Commons Attribution 4.0 International License, which permits use, sharing, adaptation, distribution and reproduction in any medium or format, as long as you give appropriate credit to the original author(s) and the source, provide a link to the Creative Commons licence, and indicate if changes were made. The images or other third party material in this article are included in the article's Creative Commons licence, unless indicated otherwise in a credit line to the material. If material is not included in the article's Creative Commons licence and your intended use is not permitted by statutory regulation or exceeds the permitted use, you will need to obtain permission directly from the copyright holder. To view a copy of this licence, visit http://creativecommons.org/licenses/by/4.0/. 


\section{Background}

Familial Mediterranean Fever (FMF) is a recurrent disease with an autosomal recessive inheritance pattern, which is presented by fever for 12 to $72 \mathrm{~h}$, attacks of abdominal, chest and joint pain. Family history is common in the progress of the disease; the most important factor in pathogenesis of the disease is pyrin dysfunction as a result of mutations on MEditerranean FeVer (MEFV) gene on the short arm of chromosome 16 [1-5].

Secondary amyloidosis is the most important and most common complication of FMF [3, 6, 7]. Despite the developments in diagnosis and treatment, FMF may progress to amyloidosis and subsequent renal failure. Amyloidosis manifests proteinuria at nephrotic limits and subsequent uremia, resulting with end-stage renal disease [8-10]. Some mutations on the MEFV gene, especially homozygote mutation of M694V were demonstrated to be associated with higher risk for amyloidosis [11-13]. Increase of certain acute phase markers such as C-reactive protein (CRP), serum amyloid A (SAA), erythrocyte sedimentation rate (ESR), and fibrinogen are detected [14-16]. Urinary microalbuminuria (uMA)/ urinary creatinine $(\mathrm{uCr})$ is analyzed to detect AA amyloidosis in these patients earlier. It was demonstrated that $\mathrm{uMA} / \mathrm{uCr}$ ratio is important for early detection of amyloidosis [17-20]. However, it is commonly accepted that more sensitive and specific markers are required in order to understand development and progression of nephropathy in patients with FMF.

Neutrophile gelatinase-associated lipocalcin (NGAL) is a member of lipocalin proteins. Members of this group are extracellular proteins which bind small and hydrophobic molecules, and play a role in cellular homeostasis [21, 22]. Urinary NGAL (uNGAL) is filtered by glomerules like other small lipocalin molecules. Almost all are absorbed through megalin receptors which are expressed in the brush border on proximal tubule, and uptaken through endocytosis. The level is eventually lower in the urine of healthy individuals. Previous studies indicated that UNGAL is a diagnostic marker in case of glomerular and tubular dysfunction [21-24]. It is accepted as an early predictive biological marker for acute renal injury and chronic renal diseases [25-27]. These findings suggest that UNGAL may be important for FMF patients in order to detect the renal disorder earlier to optimize the patient outcomes, and to achieve the recovery. The aim of the present study was to compare uNGAL and uMA levels as well as uNGAL/uCr and $\mathrm{uMA} / \mathrm{uCr}$ rates for accurate and early prediction of amyloidosis which causes renal dysfunction in FMF patients, and to investigate whether $\mathrm{uNGAL}$ and $\mathrm{uNGAL} / \mathrm{uCr}$ ratio may be used for disease monitoring.

\section{Methods}

\section{Study design and participants}

This study was performed on 40 attack-free patients who have referred Pediatric Nephrology Polyclinic of Bakırkoy Dr. Sadi Konuk Training and Research Hospital and diagnosed with FMF between February 2013 and August 2013 and 38 healthy volunteers with similar age and gender distribution. The patient group included $24 \mathrm{fe}-$ males and 16 males, whereas the control group included 22 females and 16 males. The study protocol was approved by local ethical committee of our hospital. The informed consent form was obtained from parent(s) of the patient following a detailed explanation about objectives and scope of the study in line with the principles of Helsinki Declaration of World Medical Association. All patients were receiving colchicine treatment. No patients resistant to colchicine were included in the study. None of our patients were receiving antiinterleukin-1 treatment.

\section{Laboratory tests}

Results of complete blood count, ESR, CRP, fibrinogen, SAA and urine analyses which have been performed on the patients enrolled during routine examination and tests were recorded from patient files. The initial and midstream urine samples were then collected from the patients for uNGAL, uMA and uCr analyses during referral. The urine samples taken into sterile containers were centrifuged at $4000 \mathrm{rpm}$ for $10 \mathrm{~min}$. The supernatant was stored at $-80^{\circ} \mathrm{C}$ until the time of analysis. The analysis was performed through Enzyme-Linked Immunosorbent Assay (ELISA) after collection of all samples. The Lipocalin/2 NGAL ELISA kit (Aviscera Bioscience, Inc. Santa Clara, CA), and sandwich enzyme immunoassay technique were used; results were evaluated in pg/mL. MA immunoturbidimetry [26] and spectrophotometric urinary $\mathrm{Cr}$ analysis were performed on same urine sample; results were evaluated in $\mathrm{mg} / \mathrm{dL}$. The patient and control groups were compared for uNGAL and uMA levels, uNGAL/uCr and uMA/uCr rates as well as other parameters.

\section{Statistical analysis}

Statistical analysis was performed through the statistical package SPSS software (Version 21.0, SPSS Inc. Chicago, IL, USA). If continuous variables were normal, they were defined as the mean \pm standard deviation $(p>0.05$ in Kolmogorov-Smirnov test or Shapira-Wilk $(n<30)$; and if the continuous variables were not normal, they were described as median. Comparisons between groups were applied by Student T test or OneWay ANOVA for normally distributed data; and Mann Whitney $U$ test or Kruscall Wallis test were used for the data which have not distributed normally. The categorical variables between the groups were analyzed by the Chi-square test 
or Fisher Exc. test. Univariate analyses were performed by Spearman's correlation test. Receiver operating characteristic curves (ROC curves) were constructed and the areas under curve (AUC) as well as the sensitivity (sen.), and the specificity (spec.) were estimated. A multiple logistic regression analysis was used to determine the associations between measurements; dependent variable values of $p<$ 0.05 were considered statistically significant.

\section{Results}

Demographic data and some laboratory tests results of the patients and controls were presented in Table 1 . The patient group included 16 males and 24 females; the control group included 16 males and 22 females; and there was not any statistically significant difference in gender distribution $(p=0.85)$. Similarly, there was not any statistically significant difference between the patient and control groups for age, height, and body weight average $(p=0.73$, $p=0.68, p=0.68$, respectively). The difference between systolic blood pressure (SBP) and diastolic blood pressure (DBP) averages of the patient and control groups was not statistically significant $(p>0.05)$.

There was not any statistically significant difference detected between average leukocyte, hemoglobin, hematocrit, and platelet levels in the patient and control groups $(p>$ $0.05)$. However, the mean corpuscular volume (MCV) was lower whereas CRP, fibrinogen and ESR averages were significantly higher in the patient group when compared with the control group $(p=0.01, p=0.02, p=0.002$ and $p=$ 0.006 , respectively). Spot uNGAL and uMA levels, and $\mathrm{uNGAL} / \mathrm{uCr}$ and $\mathrm{uMA} / \mathrm{uCr}$ rates were compared in the patients and controls. There was not any statistically significant difference observed in uMA level and uMA/uCr ratio of the patient and control groups $(p=0.36$ and $p=0.74$, respectively). However, uNGAL level and uNGAL/uCr ratio of FMF group was significantly higher than the control group ( $p=0.0001$ and $p=0.01$, respectively).

The ROC analysis was performed to estimate diagnostic profile of uNGAL and uNGAL/uCr in order to detect renal injury in the patient group. There was not any statistically significant difference when ROC distribution of uNGAL for differential diagnosis of FMF, and the area under the ROC curve of uNGAl level and $\mathrm{uNGAL} / \mathrm{uCr}$ ratio $(p=0.0001$ and $p=0.01$, Table 2 , Fig. 1$)$.

A logistic regression analysis was performed by adding the statistically significant parameters in the patient and control groups in order to investigate the risk factors that affect the patients. uNGAL $(p=0.0001)$ was

Table 1 Demographic data and laboratory findings in patients and controls

\begin{tabular}{|c|c|c|c|}
\hline Parameters & $\begin{array}{l}\text { Patients }(n=40) \\
\text { Mean } \pm \text { SD }\end{array}$ & $\begin{array}{l}\text { Controls }(n=38) \\
\text { Mean } \pm \text { SD }\end{array}$ & $p$ \\
\hline Sex (boys/girls) & $16 / 24$ & $16 / 22$ & 0.85 \\
\hline Age (year) & $8.94 \pm 3.73$ & $9.21 \pm 3.10$ & 0.73 \\
\hline Height (cm) & $130.15 \pm 23.06$ & $132.17 \pm 20.12$ & 0.68 \\
\hline Weight (kg) & $31.21 \pm 15.53$ & $32.66 \pm 14.97$ & 0.68 \\
\hline $\mathrm{SBP}(\mathrm{mmHg})$ & $102.25 \pm 13.00$ & $104.47 \pm 11.14$ & 0.42 \\
\hline $\mathrm{DBP}(\mathrm{mmHg})$ & $63.13 \pm 8.30$ & $65.67 \pm 8.48$ & 0.19 \\
\hline Leukocyte $\left(\mathrm{mm}^{3}\right)$ & $7.68 \pm 4.03$ & $6.73 \pm 2.19$ & 0.20 \\
\hline Hemoglobin (gr/dL) & $11.99 \pm 1.64$ & $12.56 \pm 1.03$ & 0.07 \\
\hline Hematocrit (\%) & $37.38 \pm 2.98$ & $38.08 \pm 2.83$ & 0.29 \\
\hline${ }^{*} \mathrm{MCV}(\mathrm{fL})$ & $80.00 \pm 5.40$ & $83.60 \pm 6.70$ & 0.01 \\
\hline Platelet $\left(\mathrm{mm}^{3}\right)$ & $302.356 \pm 110.206$ & $304.658 \pm 59.945$ & 0.91 \\
\hline${ }^{*} \mathrm{CRP}(\mathrm{mg} / \mathrm{dL})$ & $2.60 \pm 5.82$ & $0.38 \pm 0.79$ & 0.02 \\
\hline${ }^{*} \operatorname{ESR}(\mathrm{mm} / \mathrm{h})$ & $18.76 \pm 13.98$ & $10.18 \pm 9.17$ & 0.002 \\
\hline${ }^{*}$ Fibrinogen (mg/dL) & $314.10 \pm 67.89$ & $273.79 \pm 58.34$ & 0.006 \\
\hline Urine findings & Median (Min-Max) & Median (Min-Max) & $P$ \\
\hline $\mathrm{uMA}(\mathrm{mg} / \mathrm{dL})$ & $20.14(1.20-169.00)$ & $14.08(2.10-81.70)$ & 0.34 \\
\hline${ }^{*}$ uNGAL $(\mathrm{pg} / \mathrm{mL})$ & $2.1(0.5-11.5)$ & $0.9(0.11-3.4)$ & 0.0001 \\
\hline $\mathrm{uCr}(\mathrm{mg} / \mathrm{dL})$ & $71.95(11.00-356.65)$ & $98.53(21.20-256.70)$ & 0.06 \\
\hline $\mathrm{uMA} / \mathrm{uCr}(\mathrm{mg} / \mathrm{mg} \mathrm{Cr})$ & $0.35(0.02-2.77)$ & $0.19(0.02-2.09)$ & 0.13 \\
\hline${ }^{*} \mathrm{UNGAL} / \mathrm{uCr}(100 \times \mathrm{pg} / \mathrm{mg} \mathrm{Cr})$ & $3(1-9)$ & $1(0.1-14)$ & 0.01 \\
\hline
\end{tabular}

SD Standard Deviation, SBP Systolic blood pressure, DBP Diastolic blood pressure, MVC Mean corpuscular volume, CRP C-reactive protein, ESR Erythrocyte sedimentation rate, $U M A$ Urine microalbumine, $u N G A L$ Urine neutrophil gelatinase-associated lipocalin, $u C r$ Urine creatinine $* 0.05$ 
Table 2 The cut off, area under the curve (AUC), sensitivity and 1-specificity of uNGAL in patients with familial Mediterranean fever

\begin{tabular}{llllll}
\hline Parameters & AUC (\%95 Cl) & $\boldsymbol{p}$ & Cutoff & $\begin{array}{l}\text { Sensitivity } \\
(\mathbf{\% 9 5} \mathrm{Cl})\end{array}$ & $\begin{array}{l}\mathbf{1 - S p e c i f i c i t y ~} \\
\mathbf{( 9 5 \% ~ C l )}\end{array}$ \\
\hline UNGAL & $0.77(0.67-0.88)$ & $\mathbf{0 . 0 0 0 1}$ & 1.12 & 70.0 & 68.2 \\
UNGAL/UCr & $0.78(0.68-0.88)$ & $\mathbf{0 . 0 1}$ & 1.80 & 72.5 & 68.4 \\
\hline
\end{tabular}

Cl Confidence interval, uNGAL Urine neutrophil gelatinase-associated lipocalin, $u C r$ Urine creatinine

detected as an independent risk factor that affects FMF. Accordingly, uNGAL levels of the FMF patients are probably 3.38 times (1.74 to 6.57 ) as high as those of the control group (Table 3).

In this study, we examined the relationship between the number of attacks per year and the uNGAL and uMA in FMF patients. According to these results, a positive correlation was found between UNGAL and uNGAL/uCr and the number of attacks per year $(r=$ 0.743, $p=0.001$ and $r=0.516, p=0.001$; respectively) in children with FMF. On the other hand, no relationship was found between the annual number of attacks and uMA and uMA/uCr $(r=0.230, p=0.154$ and $r=0.034$, $p=0.835$; respectively) in FMF patients. The relations of uNGAL, uNGAL/uCr, uMA and uMA/Cr with number of attacks per year in FMF patients are shown in Tables 4.

\section{Discussion}

In the present study, we detected higher UNGAL level as well as uNGAL/uCr ratio in FMF patients than the control group. In addition, we found a positive correlation between uNGAL level and uNGAL/uCr ratio and number of attacks per year in FMF patients. Fibrinogen, CRP and ESR levels which are significant acute phase reactants for diagnosis of FMF were detected significantly higher in the patient group even the patients were not at

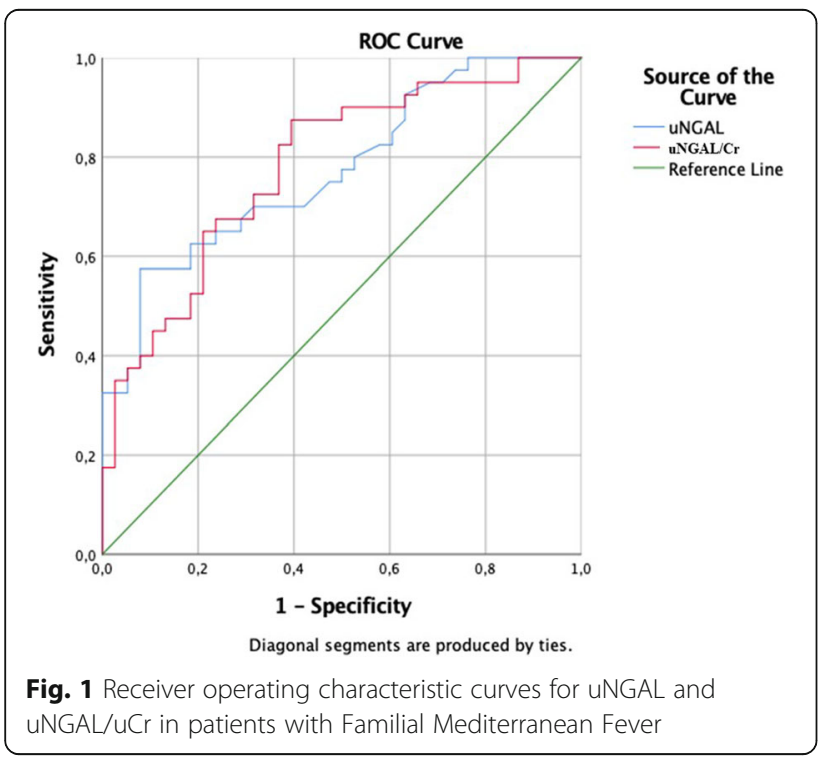

attack period. Furthermore, MCV was lower in the patient group than the control group. These findings indicate that a chronic inflammation also continues in FMF patients during attack-free period. Higher levels of spot uNGAL and $\mathrm{uNGAL} / \mathrm{uCr}$ in the patient group than the control group may indicate that such chronic inflammation may be an early indicator for renal injury in the tubules and glomerules.

We analyzed only the urine and detected UNGAL level and $\mathrm{uNGAL} / \mathrm{uCr}$ ratio in pediatric patients with FMF as compared to the healthy controls. There are a limited number of studies on the children in the literature. This study showed that renal amyloidosis should be monitored closely due to chronic inflammation in the children with FMF from early period. The increased risk in renal amyloidosis and acute inflammation attacks of serosal membrane is the most important outcome of FMF $[1,6,7]$. Amyloidosis actually appears in 50 to $60 \%$ of untreated patients, and may result with proteinuria, nephrotic syndrome, uremia, end-stage renal diseases, and death following subsequent steps [7, 28-30]. Routine urine analysis, urinary microalbuminuria and proteinuria are recommended for early diagnosis [31]. The diagnosis is confirmed by renal, rectal or abdominal fat biopsy [32]. However, like our study, microalbuminuria or proteinuria may not be detected in the early period. More sensitive and specific non-invasive tests are therefore needed. A previous study conducted on adult patients with FMF detected blood and urinary NGAL levels higher than the control group [33].

We detected CRP, ESH and SAA levels of our patients within normal reference ranges. These findings indicate

Table 3 Logistic regression analysis results in patients with familial Mediterranean fever

\begin{tabular}{llll}
\hline Parameters & Odds ratio & $\mathbf{9 5 \% ~ C l}$ & $\boldsymbol{p}$ \\
\hline Age (year) & 1.07 & $0.87-1.32$ & 0.50 \\
Fibrinogen $(\mathrm{mg} / \mathrm{dL})$ & 1.00 & $0.98-1.01$ & 0.86 \\
CRP $(\mathrm{mg} / \mathrm{dL})$ & 1.45 & $0.86-2.44$ & 0.17 \\
UNGAL $(\mathrm{pg} / \mathrm{mL})$ & 3.384 & $1.74-6.57$ & $\mathbf{0 . 0 0 0 1}$ \\
ESR $(\mathrm{mm} / \mathrm{h})$ & 1.03 & $0.944-1.128$ & 0.49 \\
\hline
\end{tabular}

CRP C-reactive protein, UNGAL Urine neutrophil gelatinase-associated lipocalin, MVC Mean corpuscular volume, ESR Erythrocyte sedimentation rate, $\mathrm{Cl}$ Confidence interval

Data are expressed as odds ratio, $95 \%$ confidence interval and $P$-values for statistical significance 
Table 4 The relations of UNGAL, UNGAL/UCr, UMA and $\mathrm{UMA} / \mathrm{Cr}$ with number of attacks per year in familial Mediterranean fever patients

\begin{tabular}{lll}
\hline Parameters & & Number of attacks per year \\
\hline UNGAL & $r$ & 0.743 \\
UNGAL/uCr & $p$ & $\mathbf{0 . 0 0 1}$ \\
& $r$ & 0.516 \\
uMA & $p$ & $\mathbf{0 . 0 0 1}$ \\
& $r$ & 0.230 \\
uMA/uCr & $p$ & 0.154 \\
& $r$ & 0.034 \\
\hline
\end{tabular}

$r$ : Correlation Coefficient

uNGAL Urine neutrophil gelatinase-associated lipocalin, $u C r$ Urine creatinine, uMA Urine microalbumine

that the patients are attack-free; however, these levels in the patients were significantly higher than those in the control group. These results are significant to indicate persistence of a subacute chronic inflammation in these patients. As a result of this inflammation, uNGAL level and $\mathrm{uNGAL} / \mathrm{uCr}$ ratio were elevated significantly through renal tubular and glomerular involvement. NGAL which is secreted from renal tubular cells secondarily to renal injury, is a protein from lipocalin family. Urinary biomarkers may be detected significantly higher from the first day of diagnosis for renal damage monitoring [34]. The important role of uNGAL was shown in pathophysiological process of chronic renal injury [26, 27]. Conventional biological markers which are used for early diagnosis of the renal injury provide positive results during late term; therefore, they may be used as early marker of acute and chronic renal injury in particular $[35,36]$. Although uNGAL indicates the progression to chronic renal damage, the levels were detected elevated in correlation with serum creatinine level in the patients who had renal transplant within the first hour following cold ischemia; and it was shown that UNGAL may be important to predict the need for dialysis within the first week [37, 38].

There is a sustained need for markers which classifies the patients into risk categories that would establish the diagnosis earlier and prevent the adverse outcomes during clinical practice. The NGAL gene which meets most of these expectations was shown as the gene which is expressed most within a short period before creatinine elevation following ischemic and nephrotoxic injury [39, 40]. Inclusion of NGAL as a diagnostic biological marker into clinical use within a short period would make a great contribution to clinical benefits and development of new therapeutic approached.

In this study, we examined the relationship between the number of attacks per year and the UNGAL and
uMA in FMF patients. According to these results, a positive correlation was found between uNGAL and $\mathrm{uNGAL} / \mathrm{uCr}$ and the number of attacks per year. This pilot study is the first to examine the correlation between UNGAL and the number of attacks per year. For this reason, we believe that the results obtained are important. If our study is supported by a controlled study with a larger series, more precise results can be obtained.

Limitation of the present study is limited number of the patients. Furthermore, duration of the disease was very short in our patients. Majority of the patients were recently diagnosed. A further study that would include the patients who are followed-up for 5 years and more may provide significant results. Nevertheless, since the present study serves as the first study on the children about this topic, our outcomes are important.

\section{Conclusion}

In conclusion, uNGAL level and $\mathrm{uNGAL} / \mathrm{uCr}$ ratio were detected higher in the pediatric patients with FMF when compared with the control group. In addition, we found a positive correlation between uNGAL level and uNGAL/uCr ratio and number of attacks per year in these children. The reason for higher levels of uNGAL during progress of other diseases is tubular injuryinduced pattern of these diseases, and secretion of NGAL from proximal tubules. However, the disease may affect the glomerules during the progress; therefore, analysis of uNGAL levels may provide significant results, especially in the patients with poor control or lack of diagnosis. Further studies with larger series are required to establish the association between FMF and UNGAL.

\section{Abbreviations}

CRP: C-reactive protein; DBP: Diastolic blood pressure; ELISA: Enzyme-Linked Immunosorbent Assay; ESR: Erythrocyte sedimentation rate; FMF: Familial Mediterranean Fever; MCV: Mean corpuscular volume; MEFV: MEditerranean FeVer; SAA: Serum amyloid A; SBP: Systolic blood pressure; uCr: Urinary creatinine; UMA: Urinary microalbuminuria; UNGAL: Urinary neutrophile gelatinase-associated lipocalcin

\section{Acknowledgements}

We thank Cagla Sariturk (statistics specialist) for statistical support.

\section{Authors' contributions \\ $\mathrm{HD}$ and SH design to the study and evaluated the laboratory findings. SCO collected patient data and wrote the article. STN made the blood analysis.} The author(s) read and approved the final manuscript.

\section{Funding}

We have not received any funding support. The authors bought the NGAL ELISA kit used in the study with their own money.

Availability of data and materials Not applicable. 


\section{Declarations}

\section{Ethics approval and consent to participate}

The study protocol was approved by the Health Sciences University, Bakırkoy Dr. Sadi Konuk Training and Research Hospital in accordance with the Declaration of Helsinki with ethical approval. Before becoming involved in the study, all participants who agreed to be involved in the study were given a cover letter describing the study objectives as well as a written informed consent form.

\section{Consent for publication}

Not applicable.

\section{Competing interests}

The authors declare that they have no competing interests.

\section{Author details}

'Dr. Sadi Konuk Training and Research Hospital Department of Pediatrics, Health Science University, Istanbul, Turkey. ${ }^{2}$ Dr. Sadi Konuk Training and Research Hospital Department of Pediatric Nephrology, Health Science University, Istanbul, Turkey. ${ }^{3}$ Okmeydani Training and Research Hospital Department of Pediatric Nephrology, Health Science University, Kaptan Paşa Mahallesi, Darülaceze Cad. No: 25 Okmeydani, 34384 Şişli//stanbul, Turkey. ${ }^{4}$ Dr. Sadi Konuk Training and Research Hospital Department of Biochemistry, Health Science University, Istanbul, Turkey.

Received: 9 October 2020 Accepted: 22 March 2021

Published online: 01 April 2021

\section{References}

1. Ben-Chetrit E, Levy M. Familial Mediterranean fever. Lancet. 1998;351(9103): 659-64. https://doi.org/10.1016/S0140-6736(97)09408-7.

2. Ozdogan H, Ugurlu S. familial Mediterranean fever. Presse Med. 2019;48(1): e61-76. https://doi.org/10.1016/j.lpm.2018.08.014.

3. Sohar E, Gafni J, Pras M, Heller H. Familial Mediterranean fever. A survey of 470 cases and review of the literature. Am J Med. 1967;43(2):227-53. https:// doi.org/10.1016/0002-9343(67)90167-2.

4. Alghamdi M. Familial Mediterranean fever, review of the literature. Clin Rheumatol. 2017;36(8):1707-13. https://doi.org/10.1007/s10067-017-3715-5.

5. Booty MG, Chae JJ, Masters SL, Remmers EF, Barham B, le JM, et al. Familial Mediterranean fever with a single MEFV mutation: where is the second hit? Arthiritis Rheum. 2009;60(6):1851-61. https://doi.org/10.1002/art.24569.

6. Konstantopoulos K, Michael S, Kanta A, et al. Renal amyloidosis as a first manifestation of familial Mediterranean fever. Scand J Rheumatol. 2000;29: 129-30.

7. Heller H, Sohar E, Gafnı J, Heller J. Amyloidosis in familial Mediterranean fever. An independent genetically determined character. Arch Intern Med. 1961;107(4):539-50. https://doi.org/10.1001/archinte.1961.03620040065007.

8. Saatci U, Ozen S, Ozdemir S, et al. Familial Mediterranean fever in children: report of a large series and discussions of the risk and prognostic factors of amyloidosis. Eur J Pediatr. 1997;156(8):619-23. https://doi.org/10.1007/ s004310050677.

9. Touitou I, Sarkisian T, Medlej-Hashim M, et al. International Study Group for phenotype-genotype correlation in familial Mediterranean fever. Country as the primary risk factor for renal amyloidosis in familial Mediterranean fever. Arthritis Rheum. 2007:56:1706-12.

10. Kasifoglu T, Bilge SY, Sari I, et al. Amyloidosis and its related factors in Turkish patients with familial Mediterranean fever: a multicenter study. Rheumatology. 2014;53:741-5.

11. Akpolat T, Özkaya O, Özen S. Homozygous M694V as a risk factorfor amyloidosis in Turkish FMF patients. Gene. 2012;492(1):285-9. https://doi. org/10.1016/j.gene.2011.10.012

12. Livneh A, Langevitz $P$, Shinar $Y$, Zaks N, Kastner DL, Pras M, et al. MEFV mutation analysis in patients suffering from amyloidosis of familial Mediterranean fever. Amyloid. 1999;6(1):1-6. https://doi.org/10.3109/13 506129908993281

13. Shohat M, Magal N, Shohat T, Chen X, Dagan T, Mimouni A, et al. Phenotype-genotype correlation in familial Mediterranean fever: evidence for an association between Met694Val and amyloidosis. Eur J Hum Genet. 1999;7(3):287-92. https://doi.org/10.1038/sj.ejhg.5200303.
14. Stankovic Stojanovic K, Hentgen V, Fellahi S, Georgin-Lavialle S, Amselem S, Grateau G, et al. Concordance between CRP and SAA in familial Mediterranean fever during attack free period: a study of 218 patients. Clin Biochem. 2017; 50(4-5):206-9. https://doi.org/10.1016/j.clinbiochem.2016.11.008.

15. Erer B, Demirkaya E, Ozen S, Kallinich T. What is the best acute phase reactant for familial Mediterranean fever follow-upandits role in the prediction of complications? A systematic review. Rheumatol Int. 2016;36(4): 483-7. https://doi.org/10.1007/s00296-015-3413-z.

16. Anton PA, Targan SR, Vigna SR, Durham M, Schwabe AD, Shanahan F. Enhanced neutrophil chemiluminescence in familial Mediterranean fever. J Clin Immunol. 1988:8(2):148-56. https://doi.org/10.1007/BF00917903.

17. Saatci U, Ozdemir S, Ozen S, Bakkaloglu A. Serum concentration and urinary excretion of beta 2-microglobulin and microalbuminuria in familial Mediterranean fever. Arch Dis Child. 1994;70(1):27-9. https://doi.org/10.113 6/adc.70.1.27.

18. Baskin E, Saatci U. Microalbuminuria in the course of familial Mediterranean fever. Nephrol Dial Transplant. 2004;19(10):2678. https://doi.org/10.1093/ndt/ gfh285.

19. Ergüven M, Emeksiz C, Deveci M, Ozlü SG. Relation between microalbuminuria and gene mutations in familial Mediterranean fever. Turk J Pediatr. 2008;50(4):326-30.

20. Uslu AU, Aydin B, Icagasıoglu IS, et al. The relationship among the level of serum amyloid $\mathrm{A}$, high-density lipoprotein and microalbuminuria in patients with familial Mediterranean fever. J Clin Lab Anal. 2016;30(6):1003-8. https:// doi.org/10.1002/jcla.21971

21. Devarajan P. Neutrophil gelatinase-associated lipocalin (NGAL): a new marker of kidney disease. Scand J Clin Lab Investig Suppl. 2008;241:89-94. https://doi.org/10.1080/00365510802150158.

22. Schmidt-Ott KM, Mori K, Li JY, Kalandadze A, Cohen DJ, Devarajan P, et al. Review dual action of neutrophil gelatinase-associated lipocalin. J Am Soc Nephrol. 2007;18(2):407-13. https://doi.org/10.1681/ASN.2006080882.

23. Devarajan P. Biomarkers for the early detection of acute kidney injury. Curr Opin Pediatr. 2011;23(2):194-200. https://doi.org/10.1097/MOP.0b013e32 8343f4dd.

24. Bolignano D, Coppolino G, Lacquaniti A, Nicocia G, Buemi M. Pathological and prognostic value of urinary neutrophil gelatinase associated lipocalin in macroproteinuric patients with worsening renal function. Kidney Blood Press Res. 2008;31(4):274-9. https://doi.org/10.1159/000151665.

25. Bolignano D, Lacquaniti A, Coppolino G, et al. Neutrophil gelatinaseassociated lipocalin (NGAL) and progression of chronic kidney disease. Clin J Am Soc Nephrol. 2009;4(2):337-44. https://doi.org/10.2215/CJN.03530708.

26. Nishida M, Kawakatsu H, Okumura Y, Hamaoka K. Serum and urinary neutrophil gelatinase-associated lipocalin levels in children with chronic renal diseases. Pediatr Int. 2010;52(4):563-8. https://doi.org/10.1111/j.1442-2 00X.2010.03067.x.

27. Bolignano D, Lacquaniti A, Coppolino G, Campo S, Arena A, Buemi M. Neutrophil gelatinase-associated lipocalin reflects the severity of renal impairment in subjects affected by chronic kidney disease. Kidney Blood Press Res. 2008:31(4):255-8. https://doi.org/10.1159/000143726.

28. Bolignano D, Cappolino G, Campo S, et al. Urinary neutrophil gelatinaseassociated lipocalin (NGAL) is associated with severity of renal isease in proteinuric patients. Nephrol Dial Transplant. 2008;23:414-6.

29. Meijer E, Boertien WE, Nauta FL, et al. Association of urinary biomarkers with disease severity in patients with autosomal dominant polycystic kidney disease: a cross-sectional analysis. Am J Kidney Dis. 2010;56(5):883-95. https://doi.org/10.1053/j.ajkd.2010.06.023.

30. Mori K, Nakao K. Neutrophil gelatinase-associated lipocalin as the real-time indicator of active kidney damage. Kidney Int. 2007;71(10):967-70. https:// doi.org/10.1038/sj.ki.5002165.

31. Assadi FK. Quantitation of microalbuminuria using random urine samples. Pediatr Nephrol. 2002;17(2):107-10. https://doi.org/10.1007/s00467-0010762-5.

32. Röcken C, Shakespeare A. Pathology, diagnosis and pathogenesis of AA amyloidosis. Virchows Arch. 2002:440(2):111-22. https://doi.org/10.1007/ s00428-001-0582-9.

33. Deveci K, Korkmaz S, Senel S, Deveci H, Sancakdar E, Uslu AU, et al. Do neutrophil gelatinase-associated lipocalin and interleukin-18 predict renal dysfunction in patients with familial Mediterranean fever and amyloidosis? Ren Fail. 2014;36(3):339-44. https://doi.org/10.3109/0886022X.2013.865486.

34. Hall IE, Coca SG, Perazella MA, Eko UU, Luciano RL, Peter PR, et al. Risk of poor outcomes with novel and traditional biomarkers at clinical AKI 
diagnosis. Clin J Am Soc Nephrol. 2011;6(12):2740-9. https://doi.org/10.221 5/CJN.04960511.

35. Guo L, Zhu B, Yuan H, Zhao W. Evaluation of serum neutrophil gelatinaseassociated lipocalin in older patients with chronic kidney disease. Aging Med. 2020;3:32-9.

36. Fuchs TC, Frick K, Emde B, Czasch S, von Landenberg F, Hewitt P. Evaluation of novel acute urinary rat kidney toxicity biomarker for subacute toxicity studies in preclinical trials. Toxicol Pathol. 2012;40(7):1031-48. https://doi. org/10.1177/0192623312444618.

37. Bolignano D, Donato V, Coppolino G, Campo S, Buemi A, Lacquaniti A, et al. Neutrophil gelatinase-associated lipocalin (NGAL) as a marker of kidney damage. Am J Kidney Dis. 2008;52(3):595-605. https://doi.org/10.1053/j.a jkd.2008.01.020.

38. Cappuccilli M, Capelli I, Comai G, Cianciolo G, La Manna G. Neutrophil gelatinase associated lipocalin as a biomarker of allograft function after renal transplantation: evaluation of the current status and future insights. Artif Organs. 2018;42(1):8-14. https://doi.org/10.1111/aor.13039.

39. Cai L, Rubin J, Han W, Venge P, Xu S. The origin of multiple molecular forms in urine of HNL/ NGAL. Clin J Am Soc Nephrol. 2010;5(12):2229-35. https:// doi.org/10.2215/CJN.00980110.

40. Ronco C, Legrand M, Goldstein SL, et al. Neutrophil gelatinase-associated lipocalin: ready for routine clinical use? An international perspective. Blood Purif. 2014;37:271-85.

\section{Publisher's Note}

Springer Nature remains neutral with regard to jurisdictional claims in published maps and institutional affiliations.

Ready to submit your research? Choose BMC and benefit from:

- fast, convenient online submission

- thorough peer review by experienced researchers in your field

- rapid publication on acceptance

- support for research data, including large and complex data types

- gold Open Access which fosters wider collaboration and increased citations

- maximum visibility for your research: over $100 \mathrm{M}$ website views per year

At BMC, research is always in progress.

Learn more biomedcentral.com/submissions 